\title{
Article \\ Effects of a Curved Heel Shape in a Running Shoe on Biomechanical Variables and Comfort
}

\author{
Sihyun Ryu ${ }^{1}{ }^{\mathbb{B}}$, Darren Stefanyshyn ${ }^{2}$, Sejin Kong ${ }^{3}$ and Sang-Kyoon Park ${ }^{4, *}$ \\ 1 Department of Taekwondo, Korea National Sport University, Seoul 05541, Korea; hope222ysh@knsu.ac.kr \\ 2 Human Performance Laboratory, University of Calgary, Calgary, AB T2N 1N4, Canada; stefanys@ucalgary.ca \\ 3 R \& D Center, LS Networks, Seoul 04386, Korea; sjkong@lsnetworks.com \\ 4 Motion Innovation Center, Korea National Sport University, Seoul 05541, Korea \\ * Correspondence: spark@knsu.ac.kr; Tel.: +82-10-5378-9617
}

Citation: Ryu, S.; Stefanyshyn, D.; Kong, S.; Park, S.-K. Effects of a Curved Heel Shape in a Running Shoe on Biomechanical Variables and Comfort. Appl. Sci. 2021, 11, 3613. https://doi.org/10.3390/app11083613

Academic Editor: Zimi Sawacha

Received: 8 March 2021

Accepted: 14 April 2021

Published: 16 April 2021

Publisher's Note: MDPI stays neutral with regard to jurisdictional claims in published maps and institutional affiliations.

Copyright: (c) 2021 by the authors. Licensee MDPI, Basel, Switzerland. This article is an open access article distributed under the terms and conditions of the Creative Commons Attribution (CC BY) license (https:// creativecommons.org/licenses/by/ $4.0 /)$.

\begin{abstract}
Background: The purpose of this study was to investigate the effects of a rounded heel shoe (RHS) and rounded lateral heel shoe (RLHS) on impact and lower extremity stability as well as their relationships with comfort during running. (2) Methods: Twenty healthy male adults participated in the study. The data were collected using eight infrared cameras while participants were running at a speed of $2.7 \mathrm{~m} / \mathrm{s}$ in three shoe conditions on an instrumented treadmill. (3) Results: The peak vertical ground reaction force (PVGRF) was statistically smaller for the RHS and RLHS compared with the normal shoes (NS) $(p<0.05)$. The range of motion of inversion-eversion at the ankle joint was statistically smaller for the RLHS compared with the NS and RHS $(p<0.05)$. Increased dorsiflexion of the ankle joint at heel contact was negatively related to the comfort of a running shoe, and increased dorsi-plantarflexion ROM was positively related to comfort. (4) Conclusions: Based on these results, a curved heel shape of a running shoe may provide a positive influence on the biomechanical function and the comfort of running shoes. Future study, including measurements of lower extremity muscle activations and long-term comfort, would be beneficial to help validate current findings and develop further applications.
\end{abstract}

Keywords: rounded heel shoe; impact variables; joint angles; comfort; running

\section{Introduction}

In running, impact is absorbed through ankle joint eversion with dorsi-flexion from when the heel contacts the ground until mid-stance [1]. It has also been suggested that excessive eversion of the foot may induce limb injury during running [2-4]. Thus, a strategy to reduce impact and maintain lower extremity joint stability is necessary to reduce injury risk factors and run efficiently $[5,6]$.

Shoes play an important role in protecting the foot and lower extremity joints [7]. Shoes not only absorb impact upon the foot's contact with the ground during various physical activities that include running but offer stability [7]. Therefore, the materials and structures of shoes are crucial factors that directly affect a human body's motion. Many previous footwear studies have examined the effect of changes in the hardness of the sole on impact and ground reaction force (GRF) variables, such as loading rate and planter pressure, as well as the ankle joint range of motion during running [8-15]. Other studies investigated changes in motion and impact with changes in other material properties of a shoe related to a shoe's thickness, elasticity and bending stiffness during running $[8,16,17]$.

While previous studies have mainly examined the effect of a shoe's material characteristics, only a few studies have investigated the influence of a shoe's structure and shape. For example, an earlier study investigated the effects of the flare at the heel of a shoe on ankle joint eversion and impact in running [18]. Recently, the biomechanical function of a rounded heel in badminton shoes has been investigated, and results showed that the vertical loading rate (VLR) was smaller with a rounded heel shoe (RHS) than other 
types of shoes during a lunge motion. Therefore, it was reported that an RHS would be effective in reducing the impact on the human body during the lunge motion in badminton. These findings suggest that an RHS may lead to a reduced impact in running, and the changes in the structure and shape of the heel are required to reduce excessive eversion and improve the stability of the ankle joint [19]. Several previous studies have speculated that heel shape would alter lower extremity biomechanics (i.e., cushioning and motion control) and comfort perception during running $[18,20]$. Therefore, a shoe manufactured with a curved heel is expected to have a positive effect on the reduction of impact as well as lower extremity stability in running.

In addition to evaluating how running shoes affect biomechanical factors, the perception of comfort is also an important factor [21]. It has been reported that overall comfort increases as loading rate decreases and the total pressure to the sole is evenly distributed [22]. Therefore, it is necessary to investigate the relevance of a shoe's subjective comfort, and examining biomechanical factors that have a positive effect on the comfort of a shoe can provide meaningful information.

The purpose of this study was to examine the effects of a curved heel shape of a running shoe (i.e., a rounded heel shoe (RHS) and rounded lateral heel shoe (RLHS)) on impact and lower extremity stability as well as relationships with comfort during running. The hypotheses of this study were as follows: first, a running shoe with a curved heel shape (RHS and RLHS) would reduce the peak vertical ground reaction force (PVGRF) and the vertical loading rate (VLR) during the stance phase, second, the RLHS would reduce the maximum eversion angle compared with the RHS and NS. In addition, changes in biomechanical variables would be closely related to shoe comfort.

\section{Materials and Methods}

\subsection{Participants}

Twenty healthy adult males (age: $23.6 \pm 2.9$ years, body mass: $71.0 \pm 8.7 \mathrm{~kg}$, and height: $175.8 \pm 5.0 \mathrm{~cm}$ ) wearing US size 9 footwear were selected as the subjects of this study. This study was approved by the University's IRB (IRB Project No.: 1263-201706-HR007-01). All the subjects who participated in this study provided written consent before the test.

\subsection{Procedure}

The subjects participated in the experiment by wearing shoes in a randomized order, and the selection of the shoes was blinded during the experiment. Each subject had a 5-10 min adaptation period to perform natural running on a treadmill (Instrumented Treadmill, Bertec, Columbus, OH, USA). Subsequently, 15 reflective markers (left and right posterior superior iliac spine, sacrum, left and right greater trochanter, right medial femoral condyle, right lateral femoral condyle, right medial malleolus, right lateral malleolus, right heel bone, right medial talus, right lateral calcaneus, right first metatarsal head, right fifth metatarsal head and right first phalanges) were attached to the lower extremity of each subject. Each subject ran at a speed of $2.7 \mathrm{~m} / \mathrm{s}$ on the treadmill where eight infrared cameras (Oqus 300, Qualisys, Göteborg, Sweden) were installed (Figure 1) [23]. Ten consecutive strides showing a consistent running pattern were collected and analyzed. The data were collected at a sampling rate of $100 \mathrm{~Hz}$ for kinematic data and $1000 \mathrm{~Hz}$ for kinetic data.

\subsection{Characteristics of the Shoes}

The normal shoes (NS) utilized were commercially available (Figure 2, left). The RHS was a modified NS with a curved shape $5 \mathrm{~mm}$ higher than the NS in the central heel (Figure 2, middle). The RLHS had a curved shape of about $15^{\circ}$ laterally, and it was manufactured $3 \mathrm{~mm}$ higher (Figure 2, right) compared with the NS. The shoes used in this study were manufactured and provided by the same manufacturer (LS Networks, Gimhae-si, Korea) to keep the shoe materials and structures the same except for the differences in the curved shape of the outsole. These modifications in heel design were based 
on biomechanical considerations regarding heel contact during running (i.e., sagittal heel strike [20,24] and toe out angles [25-27] as well as the location of impact [28]).

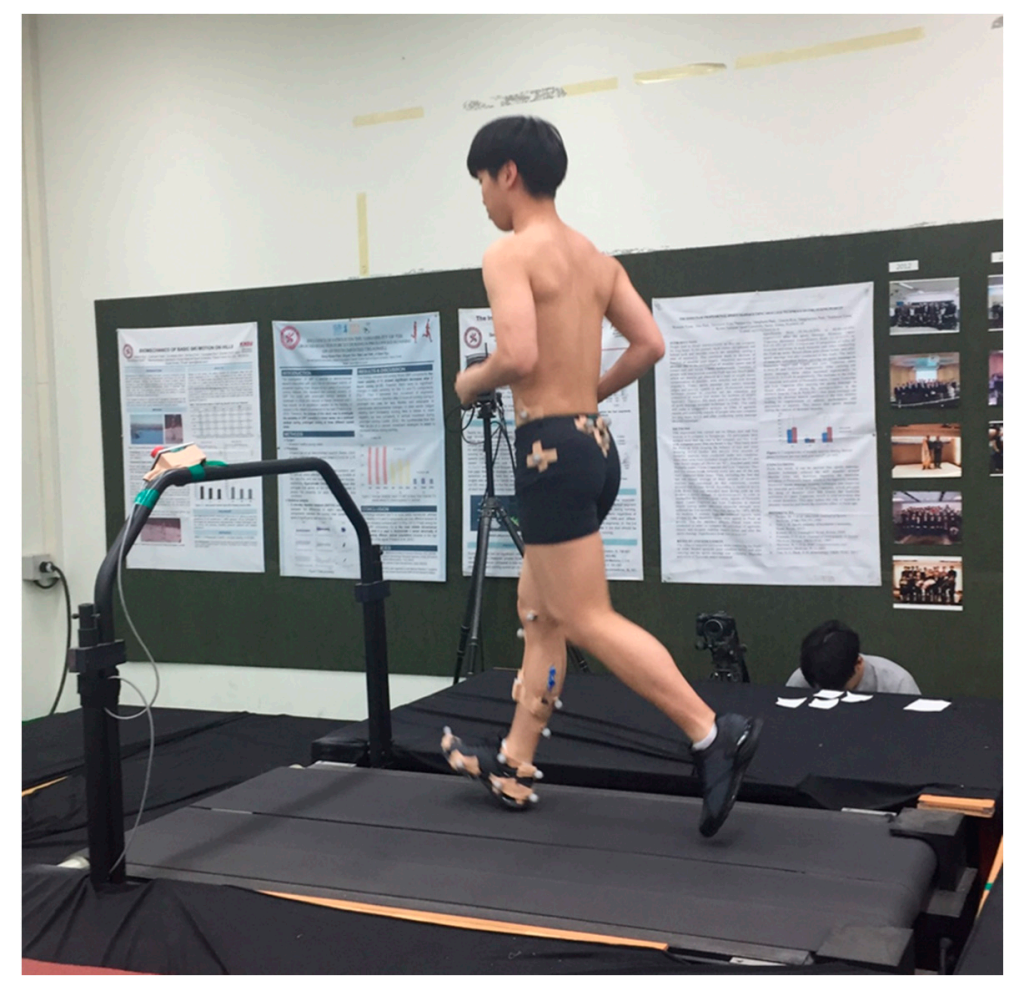

Figure 1. Experimental setting showing a participant running at $2.7 \mathrm{~m} / \mathrm{s}$ on an instrumented treadmill.

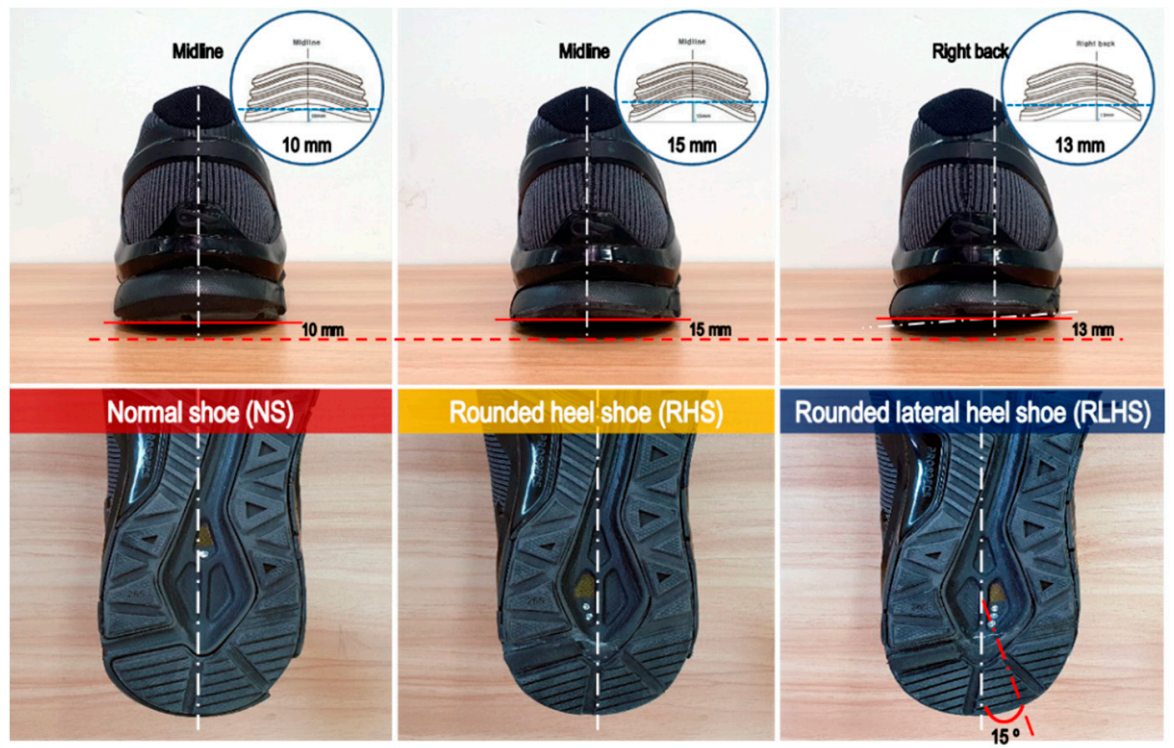

Figure 2. Rear view of the outsole of running shoes.

\subsection{Data Processing}

Ankle joint angles were analyzed with Qualisys Track Manager software (Qualisys, Goteborg, Sweden) and Matlab R2009b software (The Mathworks, Natick, MA, USA), and they were obtained through the conversion of the reflective markers' coordinate values into 3D coordinate values using the non-linear transformation (NLT) method. Smoothing 
was conducted for the kinematic data and GRF data with a Butterworth fourth-order low-pass filter to remove noise during data collection, with the cut-off frequencies being set to $6 \mathrm{~Hz}$ and $50 \mathrm{~Hz}$, respectively. The cut-off frequency was determined using a Fast Fourier Transform (FFT) analysis, calculating the Power Spectral Density (PSD) of the signals, which was converted into frequency, and then regarding $99.9 \%$ of the accumulated PSD as representative characteristics of each signal [29].

\subsection{Analysis Variables}

When PVGRF in running was observed (i.e., landing or absorbing phase), VLR was calculated by dividing the PVGRF by the time of its occurrence. Furthermore, the GRF data were normalized by body weight (BW) [30,31]. Three-dimensional Euler ankle joint angles during running were calculated relative to a neutral standing position $[29,30,32,33]$. The angle definitions were as follows: $\mathrm{x}$ axis rotation represented dorsiflexion $(+)$ and plantarflexion (-), and y axis rotation represented inversion (+) and eversion (-). Joint moments were calculated by the inverse dynamics method and normalized by each subject's mass (i.e., unit: $\mathrm{Nm} / \mathrm{kg}$ ). For comfort testing, a visual analogue scale (VAS) questionnaire was completed after the subjects wore each shoe and performed light running for 1 $\mathrm{km}$ [34-36]. The questions regarded rear foot cushioning and overall comfort.

\subsection{Statistical Processing}

To examine the differences between shoes with different heel shapes, a repeated measure one-way ANOVA was performed, and the least square difference (LSD) method was used for post-hoc analysis. To investigate the effects of biomechanical factors on the comfort perception of running shoes, a multiple regression analysis was performed. The variance Inflation Factor (VIF), which indicates multicollinearity between the independent variables, was calculated. The VIF serves as an index to judge multicollinearity, which is a precondition for the multiple regression analysis. A VIF index exceeding 4.0 implies a problem in multicollinearity. When a problem occurred, variables were removed from the highest independent variables in terms of VIF until all independent variables' VIF values were 4.0 or less [37]. SPSS Ver. 18.0 software (IBM, Armonk, NY, USA) was used, and significance was set at an alpha level of 0.05 .

\section{Results}

\subsection{Impact Variables}

PVGRFs of NS, RHS and RLHS were $1.61 \pm 0.26 \mathrm{BW}, 1.47 \pm 0.08 \mathrm{BW}$, and $1.43 \pm 0.09 \mathrm{BW}$, respectively (Figure 3, Table A1). There were significant differences between the shoes, $\mathrm{F}=5.193(p=0.010)$, the effect size was $\eta_{p}{ }^{2}=0.147$, and the statistical power was $=0.589$ with the PVGRF of both RHS and RLHS being statistically smaller than NS $(p<0.05)$.

\subsection{Ankle Joint Biomechanics}

Concerning the ankle joint inversion angle at toe-off, the value for NS was $4.0 \pm 4.5^{\circ}$, for RHS was $3.2 \pm 3.9^{\circ}$ and for RLHS was $2.3 \pm 3.7^{\circ}$ (Figure 4, Table A2, Figure A1.). There were significant differences between the shoes: $\mathrm{F}=4.305(p=0.021)$, the effect size was $\eta_{p}{ }^{2}=0.185$ and the statistical power was 0.715 . The inversion angle of the RLHS at toe-off was statistically smaller than for the NS and RHS $(p<0.05)$. As for inversion-eversion ROM during running, NS was $12.1 \pm 4.3^{\circ}$, RHS was $11.5 \pm 4.3^{\circ}$ and RLHS was $10.5 \pm 3.8^{\circ}$. There were significant differences between the shoes: $\mathrm{F}=5.041(p=0.011)$, the effect size was $\eta_{p}{ }^{2}=0.210$ and the statistical power was 0.785 . The inversion-eversion ROM of the RLHS was smaller than for the NS and RHS $(p<0.05)$. There were no significant differences in ankle joint moments between the shoes (Figure A2). 

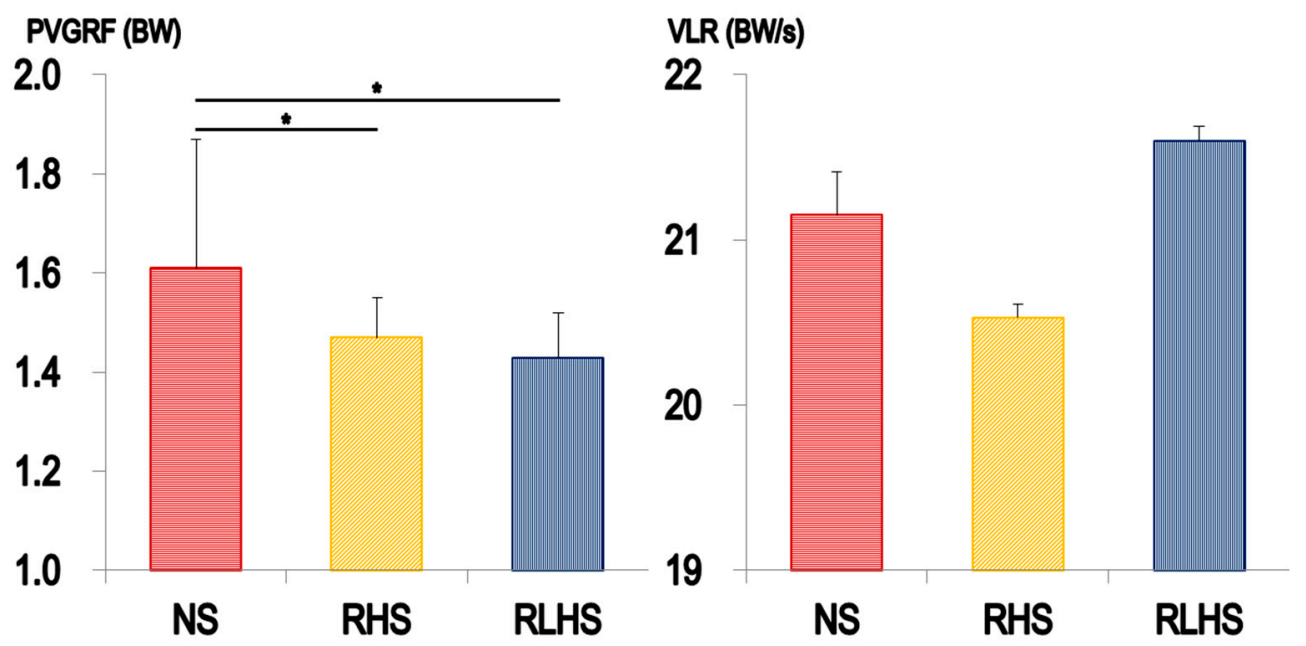

Figure 3. PVGRF (left) and VLR (right) during the stance phase of running. PVGRF: peak vertical ground reaction force, VLR: vertical loading rate, NS: normal shoe, RHS: rounded heel shoe, RLHS rounded lateral heel shoe. ${ }^{*}$ indicates a significant difference between the shoes at $\alpha=0.05$.
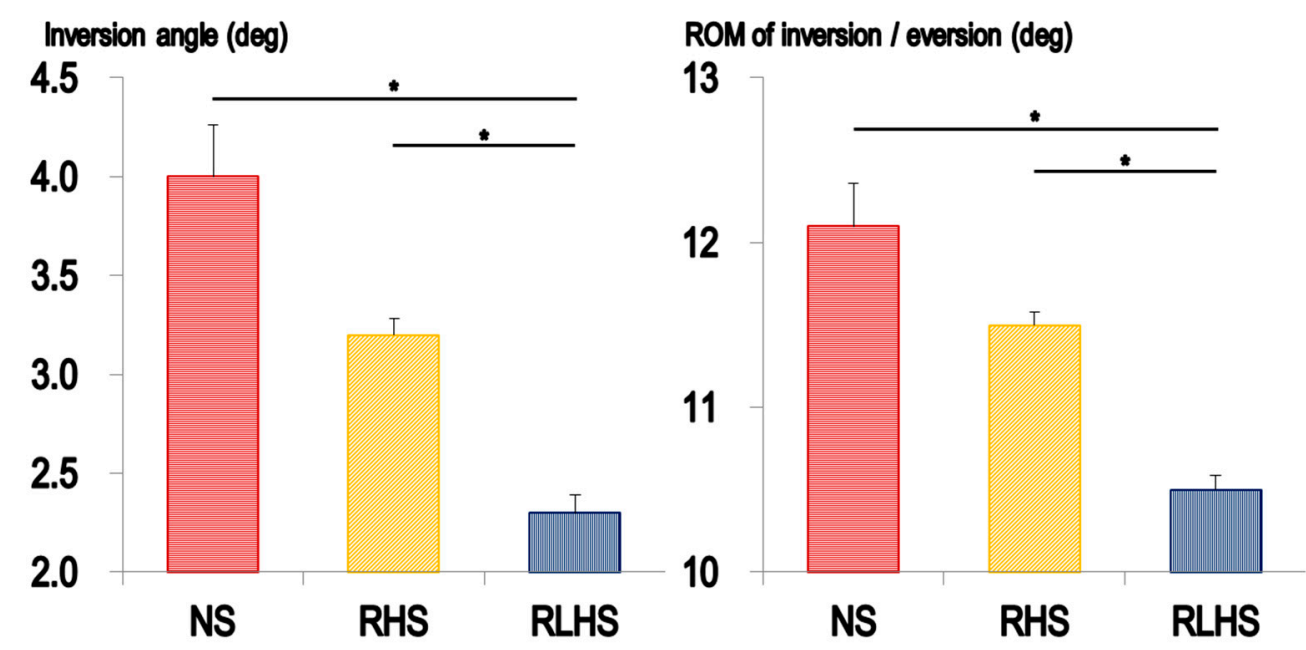

Figure 4. Inversion at toe off (left) and ROM of inversion-eversion during the stance phase of running (right). * indicates a significant difference between the shoes at $\alpha=0.05$.

\subsection{Shoe Comfort}

None of the subjective ratings showed statistically significant differences between the shoes (Table A3).

\subsection{Multiple Regression Analysis}

Figure 5 and Table A4 show the results of the multiple regression analysis for shoe comfort using the biomechanics variables. The coefficient of determination indicating the explanation power, with an R2 of 0.277 , and Durbin-Watson value of 1.437 , as well as a statistically significant model fit, was shown at $F(6,53)=3.387, p=0.007$. The estimated multiple regression equation was as follows: running shoe comfort $=-1.074$ $\times(\mathrm{VLR})-1.740 \times($ dorsiflexion angle at $\mathrm{HC})+1.021 \times($ ROM of dorsi-plantarflexion $)+$ $0.179 \times$ (inversion angle at $\mathrm{HC})-0.169 \times($ maximum eversion angle $)-1.007 \times(\mathrm{ROM}$ of inversion-eversion $)+114.619$. The dorsiflexion angle at $\mathrm{HC}(B=-0.382, t=-3.102$, $p=0.003$ ) had a statistically significant negative effect on running shoe comfort. The ROM of dorsi-plantarflexion $(~(\beta=0.271, t=-2.138, p=0.037)$ had a statistically significant positive effect on running shoe comfort. 


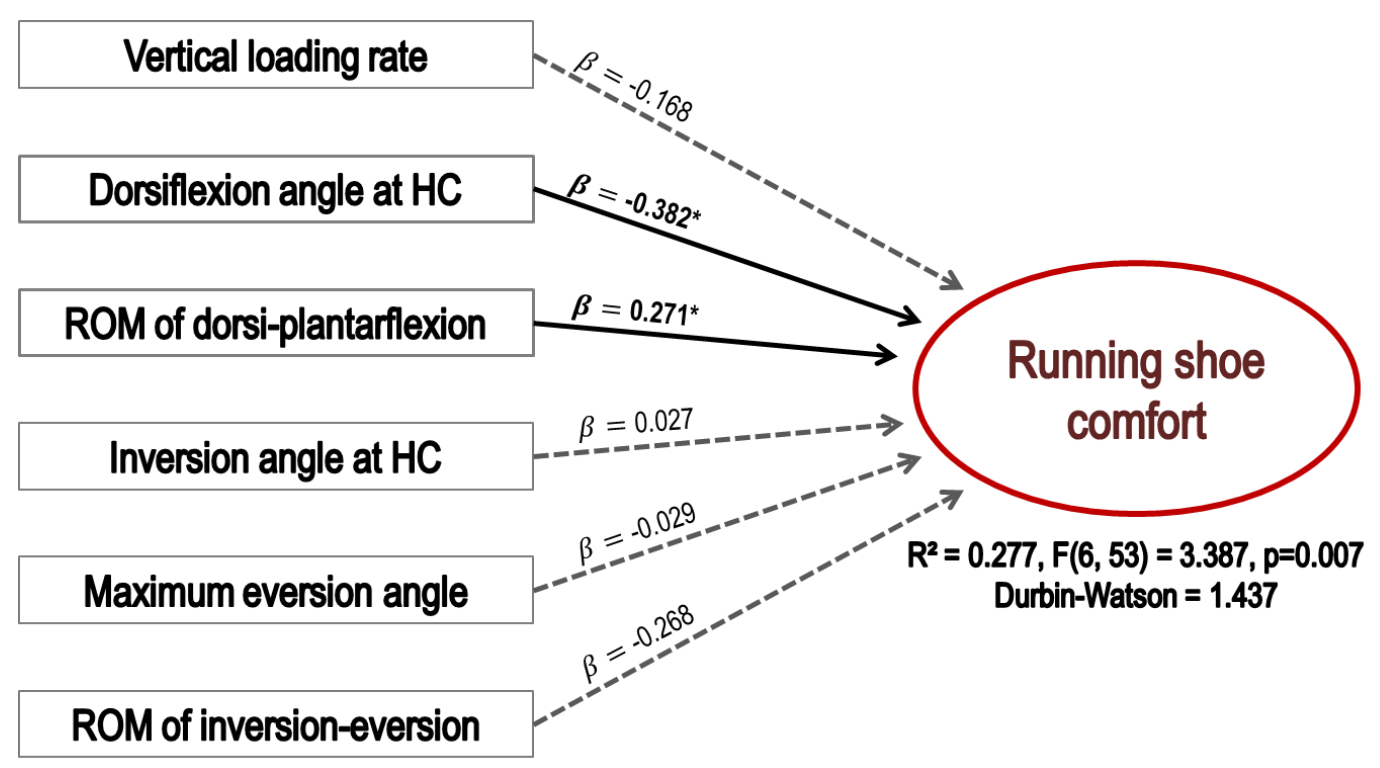

Figure 5. Diagram of multiple regression analysis for running shoe comfort using biomechanical factors. ${ }^{*}$ indicates a significant difference between the shoes at $\alpha=0.05$.

\section{Discussion}

This study aimed to investigate the effect of running shoe heel shape (RHS and RLHS) on impact variables, ankle joint biomechanics and shoe comfort and to analyze the contributions of biomechanical variables to shoe comfort using multiple regression analysis. This study was performed on runners who ran at the same speed and heel strike pattern in the three shoes, as foot strike pattern and running speed may affect running mechanics [38,39].

The first hypothesis-i.e., that a running shoe with a curved heel shape would reduce the magnitude of impact variables (i.e., PVGRF and VLR) during running - was partially accepted. No differences in VLR, which may be related to injury during running [31], were shown between the shoes. However, the PVGRF of the RHS and RLHS was smaller than that of the NS. Small reductions of impact may be beneficial to reduce the risk of running injuries, especially when repetitive high loads are more pronounced, such as in long distance running [40].

The second hypothesis-that the RLHS would reduce the maximum eversion anglewas not supported. The RLHS showed a smaller inversion-eversion ROM due to a smaller inversion angle at toe-off compared with the NS and RHS. A study has suggested that a certain level of eversion or pronation of the foot is required during running to dampen the impact shock at heel contact [31]. In addition, it has been reported that excessive eversion (i.e., greater than an eversion $\mathrm{ROM}$ of $15^{\circ}$ ) of the foot may cause discomfort and pain followed by lower extremity joint injuries in running [18,41,42]. Therefore, footwear manufacturing companies have focused on the reduction of excessive foot eversion using alterations of the shoe structure and material (i.e., heel design, heel material and hardness of the midsole), but the findings are still controversial in current studies [31]. In this study, the maximum eversion angle between the shoes did not exhibit any difference. The current finding is in accordance with the result of a previous study, in which shoes with changes in the heel flare at the side of heel had no effect on the maximum eversion during the stance phase [18].

Shoe comfort is an important factor influencing running performance as well as the incidence of lower extremity joint injury in runners [43,44]. Considering the biomechanical factors that had a positive correlation with the overall comfort of running shoes, the independent variables representing a statistically significant explanation power were dorsiflexion angle at heel contact and dorsi-plantar flexion ROM. In particular, excessive 
dorsiflexion angle at heel contact has been shown to have a negative effect on the comfort of running shoes, but an increase of dorsi-plantar flexion ROM has been shown to have a positive effect on the comfort of running shoes. Based on these results, it is believed that the proper use of rounded heel shoes, considering the natural movement [45] of dorsiplantar flexion, can help improve comfort and performance during running. Further study including more detailed information about foot kinematics and kinetics (i.e., trajectory of the center of pressure and movement coupling of the ankle joint complex) would be warranted to understand the underlying mechanism, as this would be closely related to comfort as well as running performance.

Some limitations need to be mentioned for a proper interpretation of the findings and to obtain insights into the direction of future studies. As running was performed at a slow speed of $2.7 \mathrm{~m} / \mathrm{s}$, it is not clear how running shoes with rounded heels may affect running biomechanics at higher running speeds. A further study would be required to examine running motions at faster speeds to investigate the functions of a rounded heel during these higher loading conditions. Furthermore, shoe comfort was tested during a short time period. It is important to test perceived comfort for longer periods of time and also monitor the changes in muscle activation patterns around the ankle joint to better understand the relationship between comfort and running efficiency [43]. On the other hand, depending on the shape and materials of running shoe models, natural abrasion may result in a rounding of the lateral heel to a small extent during extended wear. However, long-term use (i.e., shoe age or mileage) may decrease the functions of impact attenuation and stability because of the degradation of shoe material compared with new shoes with an originally curved heel shape [46,47].

\section{Conclusions}

In summary, this study aimed to investigate the effects of a rounded heel running shoe on impact and lower extremity biomechanics as well as their relationship with comfort during running. Based on the findings, it is concluded that the heel's curved shape showed a positive effect on the reduction of impact magnitude during running. Furthermore, the regression analysis suggests that shoe comfort is closely related to ankle kinematics in the sagittal plane. Therefore, in the development of a running shoe, dorsiflexion at heel contact and dorsi-plantarflexion ROM may be important to consider with respect to shoe comfort. Future study, including the measurements of lower extremity muscle activations and long-term comfort, would be beneficial to help validate current findings and develop further applications.

Author Contributions: Conceptualization, S.R., D.S., S.K. and S.-K.P.; investigation, S.R., D.S., S.K. and S.-K.P.; methodology, S.R., D.S., S.K. and S.-K.P.; project administration, S.K. and S.-K.P.; resources, S.K. and S.-K.P.; validation, S.R., D.S., S.K. and S.-K.P.; writing-original draft preparation, S.R. and S.-K.P.; writing - review and editing, S.R., D.S., S.K. and S.-K.P.; All authors have read and agreed to the published version of the manuscript.

Funding: This study was supported by the National Research Foundation of Korea (NRF) grant funded by Korea government (MSIT) (Grant number: 2019RIF1A1061371) and LS Networks (Seoul, Korea) (Grant number: 2017-0009).

Institutional Review Board Statement: This study is approved by the Institutional Review Board, IRB of Korea National Sport University (IRB Project Number: 1263-201706-HR-007-01).

Informed Consent Statement: Informed consent was obtained from all subjects involved in the study.

Data Availability Statement: Not applicable.

Conflicts of Interest: The authors declare no conflict of interest. 


\section{Appendix A}

Table A1. Descriptive information for impact variables during the stance phase of running.

\begin{tabular}{|c|c|c|c|c|c|c|c|c|}
\hline Variables & $\mathrm{NS}^{\mathrm{a}}$ & RHS $^{b}$ & RLHS $^{c}$ & $F$ & $p$ & Post-hoc & $\begin{array}{c}\text { Effect Size } \\
\left(\eta_{p}^{2}\right)\end{array}$ & $\begin{array}{c}\text { Statistical } \\
\text { Power }\end{array}$ \\
\hline $\begin{array}{c}\text { PVGRF } \\
(\mathrm{BW})\end{array}$ & $1.61 \pm 0.26$ & $1.47 \pm 0.08$ & $1.43 \pm 0.09$ & 5.193 & $0.010^{*}$ & $b, c<a$ & 0.147 & 0.589 \\
\hline $\begin{array}{c}\text { VLR } \\
(\mathrm{BW} / \mathrm{s})\end{array}$ & $21.15 \pm 2.90$ & $20.53 \pm 2.90$ & $21.60 \pm 2.17$ & 0.674 & 0.515 & - & 0.037 & 0.164 \\
\hline
\end{tabular}

${ }^{a}:$ NS, ${ }^{b}:$ RHS, ${ }^{c}$ : RLHS, PVGRF: peak vertical ground reaction force, VLR: vertical loading rate. ${ }^{*}$ indicates significant difference between the shoes at $\alpha=0.05$.

Table A2. Descriptive information for ankle joint angle during the stance phase of running.

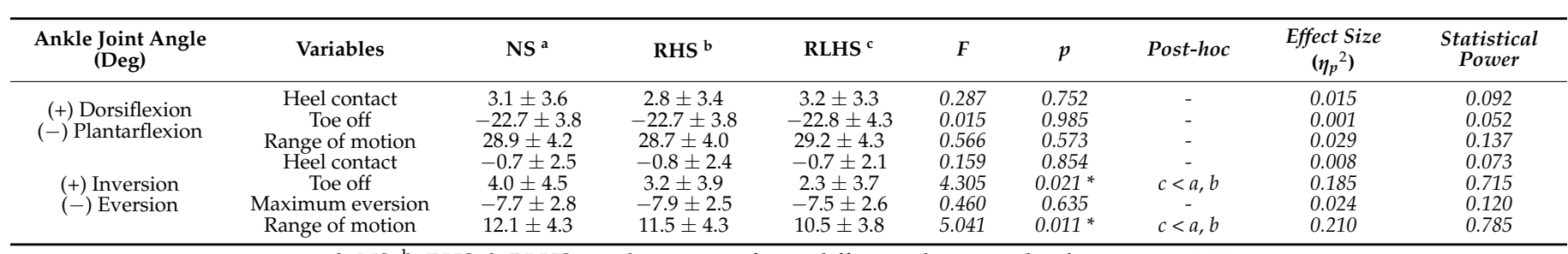

${ }^{a}:$ NS, ${ }^{b}:$ RHS, ${ }^{c}:$ RLHS, ${ }^{*}$ indicates significant difference between the shoes at $\alpha=0.05$.

Table A3. Descriptive information of comfort test.

\begin{tabular}{|c|c|c|c|c|c|c|c|c|}
\hline Questions & $\mathrm{NS}^{\mathrm{a}}$ & RHS $^{b}$ & RLHS $^{c}$ & $F$ & $p$ & Post-hoc & $\begin{array}{c}\text { Effect Size } \\
\quad\left(\eta_{p}{ }^{2}\right)\end{array}$ & $\begin{array}{c}\text { Statistical } \\
\text { Power }\end{array}$ \\
\hline $\begin{array}{c}\text { Rear foot } \\
\text { Cushioning }\end{array}$ & $57.0 \pm 14.9$ & $59.7 \pm 14.7$ & $62.1 \pm 10.7$ & 1.143 & 0.330 & - & 0.057 & 0.236 \\
\hline Overall comfort & $53.6 \pm 15.1$ & $56.7 \pm 16.6$ & $58.4 \pm 14.9$ & 0.609 & 0.549 & - & 0.031 & 0.144 \\
\hline
\end{tabular}

a: NS, ${ }^{b}$ : RHS, ${ }^{c}$ : RLHS.

Table A4. Descriptive information of multiple regression analysis for shoe comfort using biomechanical factors.

\begin{tabular}{|c|c|c|c|c|c|c|}
\hline \multirow{2}{*}{ Independent Variables } & \multicolumn{2}{|c|}{ Non-Standardized Coefficients } & \multirow{2}{*}{$\begin{array}{c}\text { Standardized } \\
\text { Coefficients }(\beta)\end{array}$} & \multirow{2}{*}{$t$} & \multirow{2}{*}{$p$} & \multirow{2}{*}{$V I F$} \\
\hline & B & Standard Error & & & & \\
\hline (constant) & 114.619 & 36.481 & & 3.142 & 0.003 & \\
\hline VLR & -1.074 & 0.975 & -0.168 & -1.102 & 0.276 & 1.705 \\
\hline Dorsiflexion angle at $\mathrm{HC}$ & -1.740 & 0.561 & -0.382 & -3.102 & $0.003 *$ & 1.114 \\
\hline ROM of dorsi-plantarflexion & 1.021 & 0.477 & 0.271 & 2.138 & $0.037 *$ & 1.176 \\
\hline Inversion angle at $\mathrm{HC}$ & 0.179 & 1.154 & 0.027 & 0.155 & 0.877 & 2.171 \\
\hline Maximum eversion angle & -0.169 & 1.133 & -0.029 & -0.149 & 0.882 & 2.679 \\
\hline ROM of inversion-eversion & -1.007 & 0.528 & -0.268 & -1.908 & 0.062 & 1.450 \\
\hline \multicolumn{7}{|c|}{$\mathrm{R}^{2}=0.277, \mathrm{~F}(6,53)=3.387, p=0.007$, Durbin-Watson $=1.437$} \\
\hline
\end{tabular}



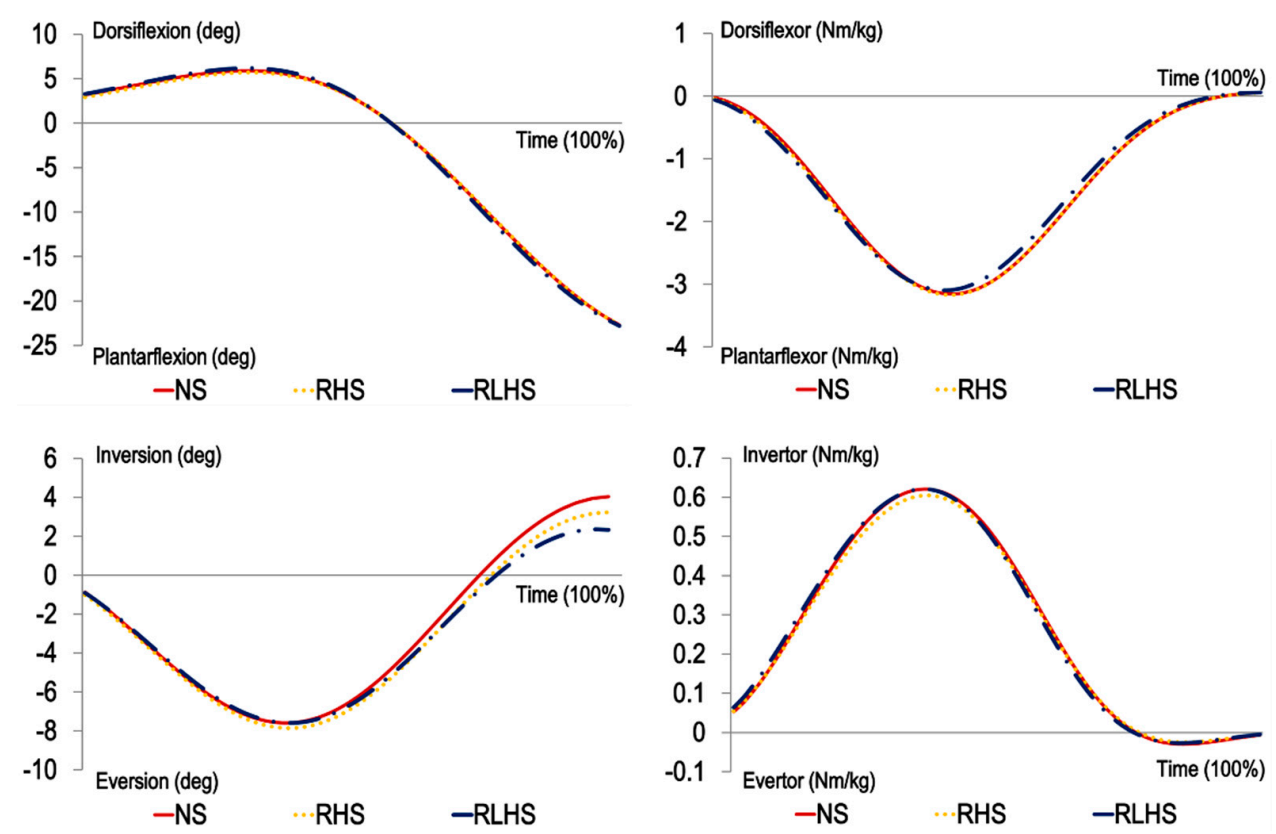

Figure A1. Comparison of ankle joint angles and moments between the shoes.
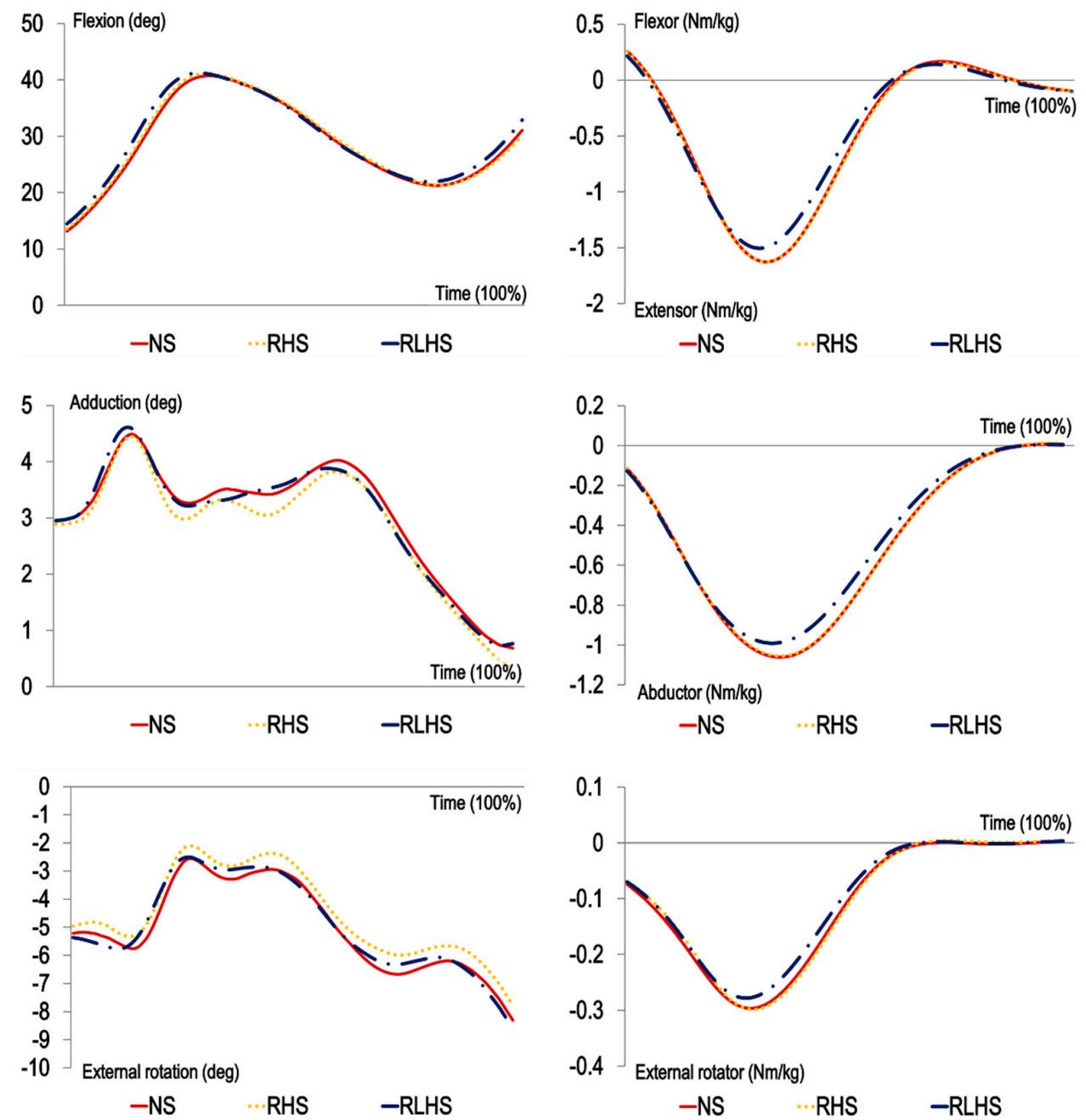

Figure A2. Comparison of knee joint angles and moments between the shoes. 


\section{References}

1. Nicola, T.L.; Jewison, D.J. The anatomy and biomechanics of running. Clin. Sports Med. 2012, 31, 187-201. [CrossRef]

2. Milner, C.E.; Davis, I.S.; Hamill, J. Free moment as a predictor of tibial stress fracture in distance runners. J. Biomech. 2006, 39, 2819-2825. [CrossRef]

3. Stefanyshyn, D.J.; Stergiou, P.; Lun, V.M.; Meeuwisse, W.H.; Worobets, J.T. Knee angular impulse as a predictor of patellofemoral pain in runners. Am. J. Sports Med. 2006, 34, 1844-1851. [CrossRef] [PubMed]

4. Willems, T.M.; De Clercq, D.; Delbaere, K.; Vanderstraeten, G.; De Cock, A.; Witvrouw, E. A prospective study of gait related risk factors for exercise-related lower leg pain. Gait. Posture 2006, 23, 91-98. [CrossRef] [PubMed]

5. Taunton, J.E.; Ryan, M.B.; Clement, D.B.; McKenzie, D.C.; Lloyd-Smith, D.R.; Zumbo, B.D. A prospective study of running injuries: The Vancouver Sun Run "In Training" clinics. Br. J. Sports Med. 2003, 37, 239-244. [CrossRef] [PubMed]

6. Yen, S.C.; Gutierrez, G.M.; Wang, Y.C.; Murphy, P. Alteration of ankle kinematics and muscle activity during heel contact when walking with external loading. Eur. J. Appl. Physiol. 2015, 115, 1683-1692. [CrossRef]

7. Nigg, B.M. Biomechanics of Running Shoes; Human Kinetics Publishers: Champaign, IL, USA, 1986.

8. Agresta, C.; Kessler, S.; Southern, E.; Goulet, G.C.; Zernicke, R.; Zendler, J.D. Immediate and short-term adaptations to maximalist and minimalist running shoes. Footwear Sci. 2018, 10, 95-107. [CrossRef]

9. Baltich, J.; Maurer, C.; Nigg, B.M. Increased vertical impact forces and altered running mechanics with softer midsole shoes. PLoS ONE 2015, 10, e0125196. [CrossRef] [PubMed]

10. Kulmala, J.P.; Kosonen, J.; Nurminen, J.; Avela, J. Running in highly cushioned shoes increases leg stiffness and amplifies impact loading. Sci. Rep. 2018, 8, 17496. [CrossRef] [PubMed]

11. Lam, W.K.; Liu, H.; Wu, G.Q.; Liu, Z.L.; Sun, W. Effect of shoe wearing time and midsole hardness on ground reaction forces, ankle stability and perceived comfort in basketball landing. J. Sports Sci. 2019, 37, 2347-2355. [CrossRef]

12. Lam, W.K.; Ng, W.X.; Kong, P.W. Influence of shoe midsole hardness on plantar pressure distribution in four basketball-related movements. Res. Sports Med. 2017, 25, 37-47. [CrossRef] [PubMed]

13. Meardon, S.A.; Willson, J.D.; Kernozek, T.W.; Duerst, A.H.; Derrick, T.R. Shoe cushioning affects lower extremity joint contact forces during running. Footwear Sci. 2018, 10, 109-117. [CrossRef]

14. Morio, C.; Lake, M.J.; Gueguen, N.; Rao, G.; Baly, L. The influence of footwear on foot motion during walking and running. J. Biomech. 2009, 42, 2081-2088. [CrossRef] [PubMed]

15. Nigg, B.M.; Bahlsen, H.A.; Luethi, S.M.; Stokes, S. The influence of running velocity and midsole hardness on external impact forces in heel-toe running. J. Biomech. 1987, 20, 951-959. [CrossRef]

16. Flores, N.; Rao, G.; Berton, E.; Delattre, N. The stiff plate location into the shoe influences the running biomechanics. Sports Biomech 2019, 1-16. [CrossRef]

17. Kurz, M.J.; Stergiou, N. Does footwear affect ankle coordination strategies? J. Am. Podiatr Med. Assoc. 2004, 94, 53-58. [CrossRef] [PubMed]

18. Nigg, B.M.; Morlock, M. The influence of lateral heel flare of running shoes on pronation and impact forces. Med. Sci. Sports Exerc. 1987, 19, 294-302. [CrossRef]

19. Lam, W.K.; Ryue, J.; Lee, K.K.; Park, S.K.; Cheung, J.T.; Ryu, J. Does shoe heel design influence ground reaction forces and knee moments during maximum lunges in elite and intermediate badminton players? PLoS ONE 2017, 12, e0174604. [CrossRef]

20. Liu, Z.L.; Lam, W.K.; Zhang, X.; Vanwanseele, B.; Liu, H. Influence of heel design on lower extremity biomechanics and comfort perception in overground running. J. Sports Sci. 2021, 39, 232-238. [CrossRef]

21. Jordan, C.; Payton, C.; Bartlett, R. Perceived comfort and pressure distribution in casual footwear. Clin. Biomech. 1997, 12, S5. [CrossRef]

22. Ryu, S.; Gil, H.; Kong, S.; Choi, Y.; Ryu, J.; Yoon, S.; Park, S.K. The effects of insole material and hardness in different plantar sites on the comfort and impact absorption. J. Erg. Soc. Korea 2018, 37, 475-487.

23. Chumanov, E.S.; Wall-Scheffler, C.; Heiderscheit, B.C. Gender differences in walking and running on level and inclined surfaces. Clin. Biomech. 2008, 23, 1260-1268. [CrossRef] [PubMed]

24. Mo, S.; Lam, W.-K.; Ching, E.C.K.; Chan, Z.Y.S.; Zhang, J.H.; Cheung, R.T.H. Effects of heel-toe drop on running biomechanics and perceived comfort of rearfoot strikers in standard cushioned running shoes. Footwear Sci. 2020, 12, 91-99. [CrossRef]

25. Cui, W.; Wang, C.; Chen, W.; Guo, Y.; Jia, Y.; Du, W.; Wang, C. Effects of toe-out and toe-in gaits on lower-extremity kinematics, dynamics, and electromyography. Appl. Sci. 2019, 9, 5245. [CrossRef]

26. Khan, S.S.; Khan, S.J.; Usman, J. Effects of toe-out and toe-in gait with varying walking speeds on knee joint mechanics and lower limb energetics. Gait. Posture 2017, 53, 185-192. [CrossRef] [PubMed]

27. McClay, I.; Manal, K. A comparison of three-dimensional lower extremity kinematics during running between excessive pronators and normals. Clin. Biomech. 1998, 13, 195-203. [CrossRef]

28. Hong, Y.; Wang, S.J.; Lam, W.K.; Cheung, J.T. Kinetics of badminton lunges in four directions. J. Appl. Biomech. 2014, 30, 113-118. [CrossRef] [PubMed]

29. Winter, D.A. Biomechanics and Motor Control of Human Movement, 4th ed.; John Wiley \& Sons, Inc.: Hoboken, NJ, USA, 2009.

30. Lung, C.W.; Chern, J.S.; Hsieh, L.F.; Yang, S.W. The differences in gait pattern between dancers and non-dancers. J. Mech. 2008, 24, 451-457. [CrossRef]

31. Nigg, B.M. Biomechanics of Sport Shoes; University of Calgary: Calgary, AB, Canada, 2010. 
32. Hamill, J.; Ryu, J. Experiment in Sport Biomechanics; Daehanmedia: Busan, Korea, 2003.

33. Yoo, S. Classification of the Hand Techniques by Angular Momentum in the Taekwondo Poomsae. Ph.D. Thesis, Graduate School of Korea National Sport University, Seoul, Korea, 2015.

34. Mundermann, A.; Nigg, B.M.; Humble, R.N.; Stefanyshyn, D. Consistent immediate effects of foot orthoses on comfort and lower extremity kinematics, kinetics, and muscle activity. J. Appl. Biomech. 2004, 20, 71-84. [CrossRef]

35. Mundermann, A.; Nigg, B.M.; Stefanyshyn, D.J.; Humble, R.N. Development of a reliable method to assess footwear comfort during running. Gait. Posture 2002, 16, 38-45. [CrossRef]

36. Mundermann, A.; Stefanyshyn, D.J.; Nigg, B.M. Relationship between footwear comfort of shoe inserts and anthropometric and sensory factors. Med. Sci. Sports Exerc. 2001, 33, 1939-1945. [CrossRef]

37. Dattalo, P. Analysis of Multiple Dependent Variables; Oxford University Press: New York, NY, USA, 2013.

38. Mercer, J.A.; Horsch, S. Heel-toe running: A new look at the influence of foot strike pattern on impact force. J. Exerc. Sci. Fit. 2015, 13, 29-34. [CrossRef] [PubMed]

39. Orendurff, M.S.; Kobayashi, T.; Tulchin-Francis, K.; Tullock, A.M.H.; Villarosa, C.; Chan, C.; Kraus, E.; Strike, S. A little bit faster: Lower extremity joint kinematics and kinetics as recreational runners achieve faster speeds. J. Biomech. 2018, 71, 167-175. [CrossRef] [PubMed]

40. Chen, W.P.; Ju, C.W.; Tang, F.T. Effects of total contact insoles on the plantar stress redistribution: A finite element analysis. Clin. Biomech. 2003, 18, S17-S24. [CrossRef]

41. McClay, I.; Manal, K. Coupling parameters in runners with normal and excessive pronation. J. Appl. Biomech. 1997, 13, 109-124. [CrossRef]

42. Stacoff, A.; Kalin, X.; Stussi, E. The effects of shoes on the torsion and rearfoot motion in running. Med. Sci. Sports Exerc. 1991, 23, 482-490. [CrossRef] [PubMed]

43. Luo, G.; Stergiou, P.; Worobets, J.; Nigg, B.; Stefanyshyn, D. Improved footwear comfort reduces oxygen consumption during running. Footwear Sci. 2009, 1, 25-29. [CrossRef]

44. Nigg, B.M.; Nurse, M.A.; Stefanyshyn, D.J. Shoe inserts and orthotics for sport and physical activities. Med. Sci. Sports Exerc. 1999, 31, S421-S428. [CrossRef] [PubMed]

45. Nigg, B.M. The role of imact forces and foot pronation: A new paradigm. Clin. J. Sport. Med. 2001, 11, 2-9. [CrossRef] [PubMed]

46. Heidenfelder, J.; Sterzing, T.; Milani, T.L. Biomechanical wear testing of running shoes. Footwear Sci. 2009, 1, 16-17. [CrossRef]

47. Kong, P.W.; Candelaria, N.G.; Smith, D.R. Running in new and worn shoes: A comparison of three types of cushioning footwear. Br. J. Sports Med. 2009, 43, 745-749. [CrossRef] [PubMed] 